\title{
Erratum to: Expression and the Role of Type 1A Serotonin Receptor in Rats' Embryonic Thymus
}

\author{
N. V. Lifantseva ${ }^{a}$, Ts. O. Koneeva ${ }^{a}$, S. N. Voronova $^{a}$, G. V. Lutsenko ${ }^{b}$, \\ L. A. Zakharova ${ }^{a}$, and V. I. Melnikova ${ }^{a, *}$ \\ ${ }^{a}$ Koltsov Institute of Developmental Biology, Russian Academy of Sciences, Moscow, 119334 Russia \\ ${ }^{b}$ Shemyakin-Ovchinnikov Institute of Bioorganic Chemistry, Russian Academy of Sciences, \\ Moscow, 117997 Russia \\ *e-mail:v_melnikova@mail.ru
}

Submitted November 20, 2020; accepted for publication November 20, 2020

DOI: $10.1134 / \mathrm{S} 1062360421310015$

Section FUNDING should read as follows:

The research was performed within the framework of State Assignment of Koltzov Institute of Developmental Biology, Russian Academy of Sciences, no. 0108-2019-0002, and was funded by the Russian Science Foundation, project number 17-14-01353.

The original article can be found online at https://doi.org/10.1134/S1062360420050057 